\title{
Intramuscular triamcinolone acetonide in chronic
} severe asthma

\author{
DT MCLEOD, SJ CAPEWELL, JENNIFER LAW, W MACLAREN, A SEATON \\ From the Chest Unit, City Hospital, and Institute of Occupational Medicine, Edinburgh
}

ABSTRACT Seventeen subjects with chronic severe asthma completed a 48 week prospective, double blind study with crossover of treatment at 24 weeks, in which triamcinolone acetonide $80 \mathrm{mg}$ intramuscularly every four weeks was compared with oral prednisolone $10 \mathrm{mg}$ daily. Spirometry, twice daily measurements of peak expiratory flow rate, and self assessment of asthma symptom scores showed significant improvement during triamcinolone treatment; less extra prednisolone was required and there was significant weight loss. Two patients withdrew, one because of dissatisfaction with prednisolone and one because of side effects while taking triamcinolone. Three were withdrawn, one with proximal muscle weakness and two because of intercurrent illness. Adrenal suppression, bruising, and hirsuitism were worse with triamcinolone, other side effects being comparable. On completion of the study 16 of the 17 patients opted to continue taking triamcinolone acetonide. This treatment is an important addition to the therapeutic options available for chronic severe asthma.

The introduction of corticosteroids revolutionised the treatment of asthma in the $1950 \mathrm{~s}^{1}$ and inhaled corticosteroids subsequently produced further substantial benefits for many asthmatics by reducing or abolishing the need for regular oral corticosteroid treatment. ${ }^{2}$ Some asthmatic patients continue to have symptoms with persistently poor ventilatory function despite continuous oral corticosteroid treatment. These patients are frequently much disabled by their disease and improve appreciably only with unacceptably high doses of corticosteroids. They therefore pose both a therapeutic dilemma and an important challenge in asthma research.

We have treated such patients with intramuscular triamcinolone acetonide for some years and have formed the impression that this often has considerable advantages for the patient, a suggestion supported by two previous studies. ${ }^{34}$ To confirm this, we selected patients with chronic severe asthma who required at least $10 \mathrm{mg}$ of prednisolone as daily maintenance treatment in addition to inhaled corticosteroids, and compared monthly intramuscular triamcinolone acetonide with daily oral prednisolone in a study using objective measurements and diary card assessment.

Address for reprint requests: Dr A Seaton, Institute of Occupational Medicine, Edinburgh EH8 9SU.

Accepted 29 April 1985

\section{Methods}

Twenty two patients agreed to take part in the study. All had longstanding asthma and had previously shown considerable variability in ventilatory function spontaneously and at least $20 \%$ improvement in FEV with corticosteroid treatment. All had required a minimum of $10 \mathrm{mg}$ oral prednisolone daily for several years as well as inhaled beclomethasone $400 \mu \mathrm{g}$ daily; with this combination all had peak flow rates less than $70 \%$ of predicted. None had suffered an exacerbation of symptoms or had needed to increase the dose of prednisolone in the four weeks before entering the study.

All patients gave written consent and the study protocol was approved by the local ethical committee. Patients were instructed in the completion of a diary card, recording twice daily peak flow rate (best of three blows), day and night symptom scores (from $0=$ "no symptoms" to $4=$ "symptoms requiring emergency treatment"), extra treatment required, and any other comments. They were examined every four weeks with measurement of FEV,$F V C$, weight, and blood pressure; urine analysis; and fundoscopy. Proximal muscle weakness was tested by asking the patient to stand upright from the squatting position five times in quick succession. Cushingoid appearance, bruising, and peripheral oedema were scored in terms of severity on a five point scale. 
In addition, on entry and at $12,24,36$, and 48 weeks a full blood count was done and concentrations of electrolytes, urea, calcium, phoshate, and alkaline phosphatase were checked. A short tetracosactrin test ( $250 \mu \mathrm{g}$ given by intramuscular injection with plasma cortisol recorded at 0 and 30 minutes) was performed on entry and at the end of each 24 week period of treatment.

We used a 48 week double blind, placebo controlled study design, with crossover of treatment after 24 weeks. Active treatment-triamcinolone acetonide $80 \mathrm{mg}$ intramuscularly every four weeks or prednisolone $10 \mathrm{mg}$ orally each day-was given to all patients along with the corresponding placebo tablets or placebo injections. Patients were randomly allocated in equal numbers to the initial active treatment and instructed to take their trial tablets early each morning. After the 48 weeks all subjects were asked to state whether they preferred the first or second 24 week treatment period, after which the code was broken.

Subjects were instructed to treat an exacerbation during the trial by taking extra prednisolone, 20 $\mathrm{mg} /$ day for at least five days, and then reduce it in their usual way. All were supplied with labelled active prednisolone for this purpose. Other treatment, such as inhaled or oral sympathomimetics, was continued unchanged throughout the study. All changes in treatment were recorded on the diary cards and at each clinic visit the remaining tablets in both the "trial" and the "active" bottles were counted.

The data were entered into a Prime 750 computer. Statistical methods were primarily descriptive, paired $t$ tests being used to test the significance of any differences observed.

\section{Results}

Twenty two subjects, 15 men and seven women (mean age 56 years, range 23-71) started the study. Two smoked 10 cigarettes daily and three were ex-smokers. Three were withdrawn from the study: one suffered a myocardial infarct 20 weeks after starting the study; one died of bronchial carcinoma, which was diagnosed at 28 weeks; and one noted increasing proximal muscle weakness at 40 weeks (16 weeks after starting triamcinolone). Two others withdrew, one because of no improvement after eight weeks of prednisolone and one because of weight loss and muscle weakness after 12 weeks of triamcinolone. Thus 17 subjects completed the study but sufficient data were collected on the patient who completed 40 weeks to permit his inclusion in the analysis.

\section{PEAK FLOW RATES: DIFFERENCES BETWEEN TREATMENTS}

The mean results of the peak flow recordings are shown in the figure. The patients who started with

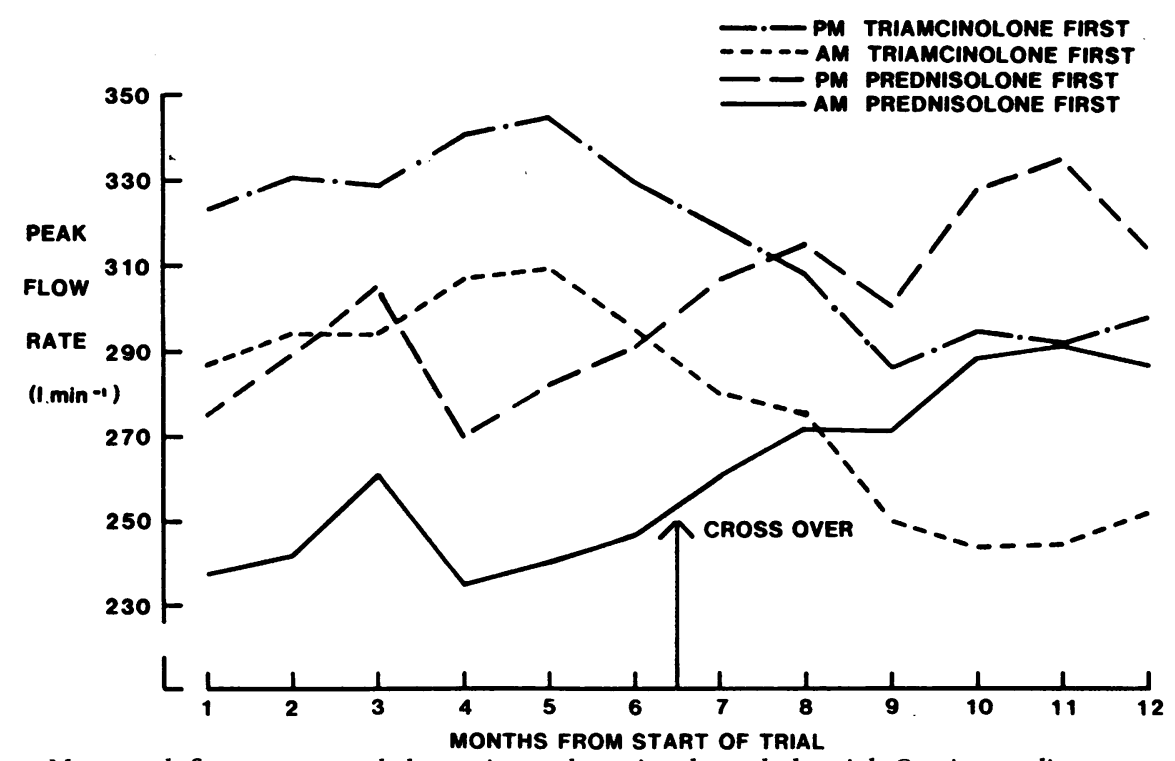

Mean peak flow rates recorded morning and evening through the trial. Continuous lines represent subjects who received triamcinolone for the first six months and interrupted lines those who received prednisolone first. 
triamcinolone had higher average peak flows at the start of the study (mean values 288 versus 2501 $\left.\min ^{-1}\right)$. This was a chance difference and did not affect the analysis as each patient was compared with himself or herself on the second treatment. Those subjects receiving triamcinolone had consistently higher readings than those receiving prednisolone throughout the first 24 weeks. After the crossover the peak flow rates of those now having triamcinolone climbed above those of the subjects now having prednisolone. The overall mean peak flow rates (PFR) were significantly higher with triamcinolone than with prednisolone $(\mathrm{p}<0.001)$ both in the morning and in the evening (table 1). Similar results were obtained when the first eight weeks of each 24 week period were excluded to avoid "carryover" effects.

\section{BUILD UP EFFECT}

The figure also illustrates a progressive rise in peak flow rates in those subjects taking triamcinolone, both in the first and in the second periods. Peak flow rates fell, however, between the fifth and sixth four week cycles, again in both periods. A significant increase was found in the morning readings during triamcinolone treatment when the mean peak flows in the first and second months were compared with those of the fourth and fifth months $(\mathrm{p}<0.05$, table 2).

\section{CARRYOVER EFFECT}

The figure shows a significant carryover effect in those treated with triamcinolone first. For those subjects, during the second 24 week period average morning peak flow readings fell from 278 litres min $^{-1}$ for the first eight weeks to $2481 \mathrm{~min}^{-1}$ for the last 16 weeks $(p<0.005)$. The comparable figures for evening readings were 314 to $2921 \mathrm{~min}^{-1}$ ( $\mathrm{p}<$ $0.005)$. This carryover effect resulted in an underestimate of the difference between the two treatments overall since the effect of triamcinolone appeared to persist for some eight to 10 weeks of the prednisolone period.

DIURNAL VARIATION IN PEAK FLOW

The mean difference between morning and evening peak flow rates during treatment with triamcinolone
Table 2 Peak flow rates with triamcinolone for months 1 and 2 compared with months 4 and 5 for 18 patients (mean values with standard deviations in parentheses)

\begin{tabular}{llll}
\hline & \multicolumn{2}{l}{ Peak flow rate $\left(l\right.$ min $\left.^{-1}\right)$} & \\
\cline { 2 - 3 } & Months 1 and 2 & Months 4 and 5 & p value \\
\hline Morning & $280(69.7)$ & $297(75.9)$ & $<0.05$ \\
Evening & $313(99.8)$ & $331(102.6)$ & $<0.1$ \\
\hline
\end{tabular}

were not significantly less than those observed with prednisolone.

VARIATION WITHIN THE FOUR WEEK CYCLE Variation within the four week cycle was examined by comparing mean readings during the second and fourth weeks for each patient (table 3 ). A clear pattern of increase in the peak flow values two weeks after the triamcinolone injection and decreased values four weeks after was apparent. The peak flow was significantly higher in week 2 than in week 4 during triamcinolone treatment $(p<0.01)$; no such difference was apparent with prednisolone.

\section{SYMPTOM SCORES}

In general, symptom scores reflected the peak flow rate results, with higher mean scores (more symptoms) during prednisolone treatment $(p<0.01$, table 1). Improvement after starting triamcinolone was apparent, though this varied considerably between individuals. A reduction in symptoms was seen in the second month in those receiving prednisolone first. This appears to be an effect of the placebo injections as there was no corresponding increase in peak flow rates.

\section{SPIROMETRY}

The mean FEV, was higher with triamcinolone both for the last 16 weeks and for the whole 24 week period. Similarly, the mean forced vital capacity values were higher with triamcinolone, though this trend did not reach significance (table 4).

\section{ADDITIONAL PREDNISOLONE}

The number of extra prednisolone tablets $(5 \mathrm{mg})$ taken to treat exacerbations was significantly greater $(\mathrm{p}<0.05)$ during prednisolone (mean 63 tablets)

Table 1 Peak flow rates and asthma symptom score values for 18 patients (mean values with standard deviations in parentheses) during treatment with triamcinolone acetonide and with prednisolone

\begin{tabular}{|c|c|c|c|c|c|c|}
\hline & \multicolumn{3}{|c|}{ Peak flow rate $\left(l \min ^{-1}\right)$} & \multicolumn{3}{|c|}{ Asthma symptom score } \\
\hline & Triamcinolone & Prednisolone & $p$ & Triamcinolone & Prednisolone & $p$ \\
\hline $\begin{array}{l}\text { Morning } \\
\text { Evening }\end{array}$ & $\begin{array}{l}287(70.0) \\
323(92.9)\end{array}$ & $\begin{array}{l}252(47.9) \\
292(82.8)\end{array}$ & $\begin{array}{l}<0.001 \\
<0.001\end{array}$ & $\begin{array}{l}1.04(0.68) \\
1.09(0.64)\end{array}$ & $\begin{array}{l}1.37(0.57) \\
1.39(0.49)\end{array}$ & $\begin{array}{l}<0.01 \\
<0.01\end{array}$ \\
\hline
\end{tabular}


Table 3 Peak flow rate values (l min $^{-1}$ ) for 18 patients: second versus fourth week during each four week cycle (mean values with standard deviations in parentheses)

\begin{tabular}{|c|c|c|c|c|c|c|}
\hline & \multicolumn{3}{|c|}{ Triamcinolone } & \multicolumn{3}{|c|}{ Prednisolone } \\
\hline & Week 2 & Week 4 & $p$ & Week 2 & Week 4 & $p$ \\
\hline $\begin{array}{l}\text { Morning } \\
\text { Evening }\end{array}$ & $\begin{array}{l}277(81.9) \\
312(104.2)\end{array}$ & $\begin{array}{l}266(78.3) \\
296(97.8)\end{array}$ & $\begin{array}{l}<0.01 \\
<0.01\end{array}$ & $\begin{array}{l}244(54.4) \\
279(88.4)\end{array}$ & $\begin{array}{l}241(52.9) \\
281(85.7)\end{array}$ & $\begin{array}{l}\text { NS } \\
\text { NS }\end{array}$ \\
\hline
\end{tabular}

Table 4 One second forced expiratory volume and forced vital capacity for 18 patients expressed as mean values (with standard deviations in parentheses) for the whole 24 week period and the last 16 weeks of the period of treatment with triamcinolone and with prednisolone

\begin{tabular}{|c|c|c|c|c|c|c|}
\hline & \multicolumn{3}{|l|}{24 weeks } & \multicolumn{3}{|l|}{ Last 16 weeks } \\
\hline & Triamcinolone & Prednisolone & $p$ & Triamcinolone & Prednisolone & $p$ \\
\hline $\begin{array}{l}\text { FEV }_{1}(1) \\
\text { FVC }^{(1)}\end{array}$ & $\begin{array}{l}1.89(0.71) \\
3.71(1.01)\end{array}$ & $\begin{array}{l}1.63(0.66) \\
3.66(1.06)\end{array}$ & $\begin{array}{l}<0.05 \\
\text { NS }\end{array}$ & $\begin{array}{l}1.84(0.67) \\
3.74(1.0)\end{array}$ & $\begin{array}{l}1.63(0.62) \\
3.68(1.1)\end{array}$ & $\begin{array}{l}<0.05 \\
\text { NS }\end{array}$ \\
\hline
\end{tabular}

than during triamcinolone treatment (mean 25 tablets).

\section{SIDE EFFECTS}

All subjects showed evidence of adrenal suppression at 24 and 48 weeks; two showed incomplete suppression on entry, suggesting previous poor compliance with prednisolone treatment. The suppression was significantly greater after the triamcinolone treatment period (table 5). Weight was significantly lower with triamcinolone, as was blood urea concentration (table 5). No other biochemical or haematological differences were found.

No lens changes developed during the study, though seven subjects had evidence of cataracts at the start. One of the three premenopausal women complained of polymenorrhoea. One subject ruptured his Achilles tendon while having triamcinolone. On the basis of a simple scoring system, 10 subjects were judged to have become more Cushingoid, seven while having prednisolone and three while having triamcinolone. Pretibial bruising was more noticeable with triamcinolone. Other side effects were similar (table 6). One patient developed peptic oesophagitis while taking prednisolone, which continued with triamcinolone and required treatment. Ten patients felt psychologically better while having triamcinolone and the mood of one depressed patient improved substantially with this treatment; mood changes in the opposite direction were not recorded. No patients, apart from the two referred to previously, developed muscular weakness.

Sixteen of the 17 patients who completed the trial preferred the triamcinolone period and opted to continue with that treatment.

\section{Discussion}

This study confirms that triamcinolone acetonide 80 $\mathrm{mg}$, given intramuscularly every four weeks, has certain advantages over oral prednisolone $(10 \mathrm{mg}$ daily) in the treatment of chronic severe asthma. Pulmonary function improved, symptoms of asthma decreased, less extra prednisolone was required, and in this group of patients side effects were no more troublesome. Moreover, most patients preferred this treatment.

These findings support those of previous investigators in showing that $80 \mathrm{mg}$ of triamcinolone

Table 5 Clinical and biochemical assessments of 18 patients (mean values with standard deviations in parentheses)

\begin{tabular}{|c|c|c|c|c|}
\hline \multirow[t]{2}{*}{ Measurement } & \multirow[t]{2}{*}{ On entry } & \multicolumn{2}{|c|}{ After 24 weeks of } & \multirow[t]{2}{*}{$p^{*}$} \\
\hline & & Triamcinolone & Prednisolone & \\
\hline $\begin{array}{l}\text { Weight (kg) } \\
\text { Basal cortisol (nmol/l) } \\
\text { Cortisol response to tetracosactrin (nmol/l) } \\
\text { Plasma urea (nmol/l) } \\
\text { Plasma potassium (mmol/l) } \\
\text { Plasma glucose (mmoll) }\end{array}$ & $\begin{array}{l}76.9(11.0) \\
147(80.9) \\
231(160.0) \\
5.1 \quad(1.24) \\
3.8 \quad(0.45) \\
5.4 \quad(1.02)\end{array}$ & $\begin{array}{l}73.6(11.4) \\
70(34.5) \\
146(76.6) \\
4.3(0.87) \\
3.7(0.31) \\
4.6(0.80)\end{array}$ & $\begin{array}{c}76.4(11.4) \\
136(82.4) \\
228(77.5) \\
5.2 \quad(1.47) \\
3.7 \quad(0.31) \\
4.9 \quad(0.9)\end{array}$ & $\begin{array}{l}<0.01 \\
<0.01 \\
<0.01 \\
<0.01 \\
\text { NS } \\
\text { NS }\end{array}$ \\
\hline
\end{tabular}

*Tabulated p values refer to paired $t$ tests comparing assessments at the ends of 24 week periods.

Conversion: SI to traditional units-Cortisol: $1 \mathrm{nmol} / \mathrm{l}=0.036 \mu \mathrm{g} / 100 \mathrm{ml}$; urea: $1 \mathrm{mmol} / \mathrm{l}=6.024 \mathrm{mg} / 100 \mathrm{ml}$; potassium: $1 \mathrm{mmol} / 1=$ $1 \mathrm{mEq} / \mathrm{l}$; glucose: $1 \mathrm{mmol} / \mathrm{l}=18 \mathrm{mg} / 100 \mathrm{ml}$. 
Table 6 Numbers of patients developing side effects

\begin{tabular}{lcc}
\hline Side effect & Triamcinolone & Prednisolone \\
\hline Bruising & & \\
$\quad$ Arms and hands & 10 & 10 \\
$\quad$ Shins & $4^{*}$ & 1 \\
Muscle weakness & 2 & 0 \\
Muscle pain & 6 & 4 \\
Ankle oedema (intermittent) & 3 & 2 \\
Facial hirsuitism & 3 & 1 \\
Increased Cushingoid & 3 & 7 \\
$\quad$ appearance & 3 & \\
\hline
\end{tabular}

*There was more pretibial bruising with triamcinolone;

acetonide every 28 days, equivalent to $2.86 \mathrm{mg} /$ day, is more effective than $10 \mathrm{mg}$ of prednisolone daily. ${ }^{34}$ This suggests that triamcinolone acetonide is more potent in terms of its effect on the airways, though not necessarily so in respect of systemic side effects and adrenal suppression. Such a view is supported by a study in which significantly less adrenal suppression was noted with triamcinolone acetonide ${ }^{4}$ and by another in which no greater suppression was found after two years' treatment with triamcinolone acetonide. ${ }^{3}$ Our finding of greater adrenal suppression with triamcinolone acetonide may be due to our studying an older age group with more severely impaired adrenals before entry, as a result of previous prolonged prednisolone treatment. Others, using $60 \mathrm{mg}$ intramuscularly every four to six weeks, have found that adrenal recovery occurs before the next injection in half of the patients. ${ }^{56}$ To judge by experience from the disciplines of dermatology and rheumatology, where triamcinolone acetonide 40-60 mg every four to six weeks has been used widely, major side effects have been remarkably few. ${ }^{7}$ Menstrual irregularities in half of the premenopausal women have been reported, resulting from altered levels of gonadotrophins and ovarian hormones. ${ }^{8}$ Patients tend to lose weight, not always a bad thing in chronic asthmatics, perhaps because of loss of fat or less salt and water retention; the possibility of subclinical myopathy remains speculative. Blood glucose and electrolyte concentrations are unaffected. In our wider experience outside this study, proximal myopathy occurs in about $5 \%$ but this complication should not be exaggerated, being easily detected and reversible. Bruising is more notable, particularly in those over 60 years of age. ${ }^{7}$ The risk of osteoporosis has not been assessed and merits further study. Long term side effects may be further reduced by using triamcinolone acetonide judiciously. It may be possible in individual patients to reduce the injection dose as well as to extend the interval between injections from four to six or even eight weeks.

Transferring asthmatic patients from oral to parenteral long acting corticosteroid treatment is not a new idea. Methyl prednisolone acetate given every two weeks has been shown to lessen the overall severity of asthma symptoms. ${ }^{9}$ This intermittent high dose "pulse" corticosteroid treatment has been shown in other diseases to alter alveolar macrophage function in a dose dependent fashion, decrease the level of immune complexes, alter alveolar macrophage function, and reduce the number of neutrophils in the lung, ${ }^{10}$ yet even in high dosage is remarkably safe. After the injection of triamcinolone acetonide the peak plasma concentration is achieved within three to 48 hours, after which there is a steady decline until the drug is virtually undetectable in plasma after 21 days. ${ }^{11}$ Thus clinical activity, while being reduced somewhat in the fourth week, lasts much longer than the period during which the drug is detectable. Monthly injection of triamcinolone acetonide is, in essence, a form of such "pulse" treatment with high plasma concentrations, particularly in the first week. This may be one of its antiasthma mechanisms.

The relative potency of different corticosteroids is clearly important in interpretation of our results. Cautious interpretation is required, as estimation of potency depends not only on the animal model but also on the target organ or tissue tested and the route of administration. Experiments on rats or mice, species sensitive to corticosteroids, may bear no relationship to what occurs in man, with his relative resistance to corticosteroids. More than 20 years ago modified corticosteroids with unusually high topical potency on human skin were developed by forming 16,17 -acetonides or by esterification at the 17 or 21 position (or both). By this means the topical anti-inflammatory activity 'was much increased while the systemic glucocorticoid effects were little changed. A vasoconstriction assay on human skin using alcohol solutions of corticosteroids under occlusive dressings showed that the relative topical potency of dexamethasone to triamcinolone acetonide to beclomethasone dipropionate was 0.8:100:500.'2 Given intravenously, however, beclomethasone dipropionate was equivalent to dexamethasone in lowering cortisol (implying a similar systemic glucocorticoid effect). While triamcinolone acetonide is about 100 times more potent than dexamethasone on human skin, its relative potency with respect to reduction of plasma cortisol does not appear to have been investigated.

One of the actions of corticosteroids leads to the synthesis of a factor that blocks phospholipase A2, thus preventing the biosynthesis of a whole cascade of lipid mediators. ${ }^{13}$ The potency of this inhibition closely parallels anti-inflammatory activity. If therefore a local anti-inflammatory effect within the airway were a critical factor in the unique efficacy of 
corticosteroids in asthma, and if this effect within the bronchial mucosa were relatively greater than the systemic glucocorticoid effect, the benefits would outweigh potential side effects.

Most patients with asthma respond to prednisolone and we see no reason for changing the general use of this well tried drug. Growing awareness of the problem of steroid resistant patients, ${ }^{14}$ however, raises the possibility that individual variation in steroid cell membrane receptors may also alter the clinical response. Triamcinolone acetonide, for reasons still poorly understood, appears to offer a valuable alternative to prednisolone in chronic severe asthma. It has the advantage of guaranteed compliance and it appears to be acceptable to most of our patients.

We are most grateful to Catherine McLennan, Morag McVittie, and ABH Hunter from the City Hospital, Edinburgh; R Murdoch from the Institute of Occupational Medicine; Dr PH Lacey of Pfizer Ltd; and P Woods of ER Squibb and Sons Ltd; and to Joyce Holywell and Elizabeth Crolla for typing the manuscript. Dr Peter Howard gave us the original idea.

\section{References}

1 Walsh SD, Grant IWB. Corticosteroids in treatment of chronic asthma. Br Med J 1966;ii:796-802.

2 British Thoracic and Tuberculosis Association. Inhaled corticosteroids compared with oral prednisolone in patients starting long-term corticosteroid therapy for asthma. Lancet 1975;ii:469-73.

3 Peake MD, Cayton RM, Howard P. Triamcinolone in corticosteroid-resistant asthma. Br J Dis Chest 1979; 73:39-44.

4 Willey RF, Fergusson RJ, Godden DJ, Crompton GK, Grant IWB. Comparison of oral prednisolone and intramuscular deport triamcinolone in patients with severe chronic asthma. Thorax 1984;39:340-4.

5 Mikhail GR, Sweet LC, Mellinger RC. Parenteral long-acting corticosteroids: effect on hypothalamicpituitary-adrenal function. Ann Allergy 1973; 31:337-43.

6 Droszcz W, Lech B, Malunowicz E, Piotrowska B. Factors influencing adrenocortical suppression during long-term triamcinolone acetonide therapy in asthma. Ann Allergy 1980;44:174-6.

7 Arnold HL. Safer long-term steroid therapy with injected triamcinolone acetonide. Int J Dermatol 1978;17:216-7.

8 Carson TE, Daane TA, Weinstein RL. Long-term intramuscular administration of triamcinolone acetonide. Arch Dermatol 1975;111:1585-7.

9 Nash J, Jacomb RG. Corticosteroid therapy in chronic asthma. Practitioner 1968;201:358-61.

10 Keogh TA, Bernardo J, Hunninghake GW, Price DL, Crystal RG. Effect of intermittent high dose parenteral corticosteroids on the alveolitis of idiopathic pulmonary fibrosis. Am Rev Respir Dis 1983;127:18-22.

11 Kusama M, Sakauchi N, Kumaoka S. Studies of plasma levels and urinary excretion after intramuscular injection of triamcinolone acetonide. Metabolism 1971; 20:590-6.

12 Harris DM. Some properties of beclomethasone diproprionate and related steroids in man. Postgrad Med J 1975;51,suppl 4:20-5.

13 Flower RJ, Blackwell GJ. Anti-inflammatory steroids induce biosynthesis of a phospholipase $A_{2}$ inhibitor which prevents prostaglandin generation. Nature 1979;278:456-9.

14 Carmichael J, Paterson IC, Diaz P, Crompton GK, Kay AB, Grant IWB. Corticosteroid resistance in chronic asthma. Br Med J 1981;282: 1419-22. 